\title{
Análisis de tecnologías digitales para beneficiar el ejercicio profesional de los mediadores familiares de Chile*
}

\section{Sofía Andrea Alarcón García**}

RESUMEN. En este estudio analizamos tecnologías digitales que pudieran beneficiar el ejercicio profesional de los mediadores familiares de Chile. Sostenemos la hipótesis de que existen tecnologías digitales que podrían contribuir a resguardar principios de la mediación, favorecer la comunicación, gestionar las emociones y la búsqueda de acuerdos, en armonía con las leyes 19.968 y 19.628 de Chile. Nuestros resultados muestran doce tecnologías digitales compatibles con nuestra hipótesis. Concluimos que estas tecnologías contribuyen al ejercicio profesional de los mediadores, siempre que no afecten su desempeño global y no transgredan derechos fundamentales o la teoría de la mediación.

PALABRAS ClAVE: mediación familiar, mediador familiar, tecnologías digitales.

\section{Digital Technologies to Benefit the Professional Exercise of Family Mediators in Chile}

ABSTRACT. In this study, I analyze digital technologies that could benefit the professional practice of family mediators in Chile. I supported the hypothesis that there are

* Fecha de recepción: 7 de octubre de 2019. Fecha de aceptación: 30 de marzo de 2020.

Para citar el artículo: AlARCón GARCíA, S. A., "Análisis de tecnologías digitales para beneficiar el ejercicio profesional de los mediadores familiares de Chile", Revista de Derecho Privado, n. ${ }^{\circ} 39$, julio-diciembre 2020, 33-60, DoI: https://doi.org/10.18601/01234366.n39.03.

** Centro de Resolución Alternativa de Conflictos (CREA), Universidad Católica del Temuco, Temuco, Chile. Magíster en Resolución colaborativa de conflictos y Licenciada en Ciencias Jurídicas, Universidad Católica del Temuco, Temuco, Chile. Contacto: sag.abogada@gmail.com. Orcid: 0000-00032655-7512. 
digital technologies that could contribute to safeguarding principles of mediation, favoring communication, managing emotions, and seeking agreements, in harmony with Chilean laws 19.968 and 19.628. The results show twelve digital technologies compatible with my hypothesis. I conclude that these technologies contribute to the professional practice of mediators but must not affect their overall performance and do not violate fundamental rights or the theory of mediation.

KEYWORDS: family mediation, family mediator, digital technologies.

Sumario: Introducción. I. Antecedentes teóricos. II. Resultados de la investigación. III. Discusión. Conclusiones. Referencias.

\section{Introducción}

Las tecnologías digitales se desarrollan a partir de la conversión de señales analógicas a digitales ${ }^{1}$. Dicho proceso inicia con la extracción de muestras de amplitud de una señal continua a intervalos regulares de tiempo. Luego, cada muestra es cuantificada y se le asigna un valor de amplitud discreto, es decir, un valor dentro de un conjunto finito de niveles en función de la amplitud original. Finalmente, los valores cuantificados se traducen a código binario u otros códigos digitales ${ }^{2}$. Nosotros definiremos las tecnologías digitales como unidades de procesamiento capaces de almacenar o ejecutar señales codificadas digitalmente o de realizar la digitalización de señales analógicas a través del muestreo, la cuantificación y codificación de la información.

Las tecnologías digitales ofrecen un sinfín de beneficios en los distintos ámbitos del quehacer cotidiano, sin embargo, su uso también puede significar un riesgo para la vida privada de las personas. La mayor parte de los estados democráticos del mundo, conscientes de este problema, han desarrollado leyes para proteger la información personal que se trata a través de medios digitales ${ }^{3}$. No obstante, la irrefrenable expansión de nuevas tecnologías digitales constituye un desafío constante para las legislaciones vigentes ${ }^{4}$. Chile consagró la protección de la vida privada a nivel constitucional en el año 1980, y en 1999 se dictó la Ley n. ${ }^{\circ} 19.628$ sobre pro-

1 El término analógico se refiere a una magnitud o un dato continuo; es decir, una magnitud en la cual, entre dos valores cualesquiera, siempre existirá un valor intermedio. Por el contrario, denominamos digital a una magnitud discreta o diferenciada, que puede tomar un conjunto finito de valores. MorALes, G. y García, J., Sistemas y circuitos eléctricos, Madrid, Parainfo, 2013, 115.

2 Morales, G. y García, J., Sistemas y circuitos eléctricos, Madrid, Paraninfo, 2013, 115.

3 Organización para la CoOperación y el Desarrollo Económicos, Perspectivas de la ocde sobre la economía digital 2017, Ciudad de México, ocDE, 2017, 24; 104.

4 El ejemplo más reciente que muestra los esfuerzos por modernizar la legislación en atención a las nuevas tecnologías lo constituye el Libro Blanco sobre Inteligencia Artificial de la Unión Europea, publicado el 19 de febrero de 2020, disponible en [https://op.europa.eu/es/publication-detail/-/publication/aace9398-594d-11ea-8b81-01aa75ed71a1] [consultado el 16 de marzo de 2020]. 
tección de la vida privada en el ámbito civil. No obstante, con la mencionada ley solo se reguló el tratamiento de datos personales por parte de terceros en registros o bancos de datos, incluyendo los procedimientos u operaciones realizados mediante tecnologías digitales 5 .

La mediación es un mecanismo de resolución colaborativa de conflictos. En Chile, dicho mecanismo emergió como política pública en el año 2004, luego de la promulgación de la ley n. ${ }^{\circ}$ 19.968, que creó los tribunales de familia y el Sistema Nacional de Mediación Familiar. La regulación legal de la mediación familiar se contiene en el título v de la referida ley, denominado "De la mediación familiar".

El proceso de mediación está compuesto por tres fases: la premediación, la mediación propiamente dicha y la posmediación. En términos generales, en la premediación y la posmediación se agrupan todas aquellas actividades relacionadas con la preparación y el cierre de la mediación propiamente dicha. La mediación propiamente dicha es la etapa que reúne a dos o más personas en conflicto con un profesional imparcial denominado mediador, a quien le corresponde efectuar el discurso inicial, resguardar los principios de la mediación, favorecer la comunicación, gestionar las emociones, conducir el proceso hacia la búsqueda de acuerdos y redactar el acta de acuerdo o cierre de la causa.

Las investigaciones internacionales sobre la mediación familiar, el Sistema Nacional de Mediación Familiar de Chile y los documentos oficiales que regulan la prestación del servicio muestran que en el ejercicio profesional de los mediadores familiares el uso de tecnologías digitales se vincula solo a la redacción de actas de acuerdo o de cierre de las causas. En Chile no hay información sistematizada que dé cuenta de si existen tecnologías digitales con el potencial de beneficiar otras labores, distintas de la redacción de actas; o documentos que expliquen si existen impedimentos normativos que obsten el uso de más tecnologías digitales en dicho contexto. Por ello, actualmente no se conoce si el ejercicio profesional de los mediadores familiares de Chile podría verse beneficiado del uso más tecnologías digitales.

Nuestra hipótesis es que existen tecnologías digitales que podrían contribuir a resguardar los principios de la mediación, favorecer la comunicación, gestionar las emociones y conducir el proceso hacia la búsqueda de acuerdos, en armonía con leyes n. ${ }^{\circ} 19.968$ y n. ${ }^{\circ} 19.628$. De este modo, nuestro objetivo general es demostrar que el ejercicio profesional de los mediadores familiares de Chile podría beneficiarse del uso de más tecnologías digitales. Nuestro primer objetivo específico consiste en identificar tecnologías digitales que podrían beneficiar labores profesionales distintas de la redacción de actas en la mediación propiamente dicha, y el segundo objetivo específico consiste en demostrar que el uso de tales tecnologías es compatible con la normativa chilena que regula la mediación familiar y el derecho de protección a la vida privada.

5 Biblioteca del Congreso Nacional de Chile, Historia de la Ley n..$^{\circ}$ 19.628, 1999, 87, disponible en [www.bcn.cl/historiadelaley/nc/historia-de-la-ley/6814/] [consultado el 7 de octubre de 2019]. 
Para evaluar nuestra hipótesis desarrollamos un estudio documental con enfoque cualitativo. Nuestra metodología inició con una búsqueda de tecnologías digitales en revistas indexadas en Scopus, Web of Science, ScienceDirect y ProQuest, utilizando parámetros y palabras claves, en español e inglés, relacionados con las cuatro labores profesionales del mediador familiar mencionadas en la hipótesis, tales como: "tecnologías para favorecer la comunicación", "tecnologías para gestionar emociones", "tecnologías para la resolución de conflictos”. Simultáneamente, con base en los mismos criterios orientadores, efectuamos una búsqueda documental en páginas virtuales, para identificar tecnologías digitales disponibles en Chile pero no reportadas en artículos de investigación, con el fin de reflejar el contexto tecnológico actual existente en el país. Describimos las funciones, las características de funcionamiento y los requerimientos operativos de cada una de las tecnologías digitales encontradas e identificamos los potenciales beneficios que cada una de ellas podía ofrecer a las labores profesionales del mediador familiar consideradas en la hipótesis. Luego, confrontamos los antecedentes anteriores con aquello que dispone el título v de la ley n. ${ }^{\circ} 19.968$, "De la mediación familiar", y la ley n. ${ }^{\text {o }} 19.628$ sobre protección de la vida privada, para determinar si los mediadores de Chile podrían hacer uso de cada tecnología digital en la mediación propiamente dicha en armonía con los derechos de protección de los datos personales de los usuarios del servicio. De este modo, clasificamos una tecnología digital como apta según la ley en análisis cuando no existía impedimento legal para que el mediador hiciera uso de ella en beneficio de sus labores; como no apta pero adaptable si con actuaciones previas, coetáneas o posteriores al uso de la tecnología, de parte de los usuarios o del mediador, era posible dar cumplimiento a los requisitos legales exigidos para su uso; y como no apta según la ley si lo anterior no resultaba posible.

A través de esta investigación aspiramos a aportar conocimientos teóricos con rigor científico -anteriormente inexistentes- sobre los potenciales beneficios que podría aportar el uso de tecnologías digitales al ejercicio profesional de los mediadores familiares de Chile. Asimismo buscamos extender la incipiente doctrina internacional que vincula el uso de tecnología digital con la mediación familiar. Todo lo anterior, con el fin de acercar a los mediadores familiares a los procesos de cambio actuales y emergentes promovidos por las tecnologías digitales.

Nuestro trabajo se organiza en cuatro secciones: en la primera de ellas presentamos los antecedentes teóricos en que fundamos la investigación; en las secciones segunda y tercera exponemos y discutimos los resultados obtenidos; y en la cuarta sección terminamos con la presentación de nuestras conclusiones.

\section{Antecedentes teóricos}

\section{A. El proceso de mediación familiar en Chile}

La mediación familiar emergió como política pública en Chile en el año 2004, con la promulgación de la ley n. ${ }^{\circ} 19.968$, que creó los tribunales de familia y el Sistema 
Nacional de Mediación Familiar ${ }^{6}$. Este servicio se implementó anexo a los tribunales de familia, para garantizar y ampliar el acceso de los ciudadanos a la justicia de familia, hacer más heterogénea la tutela de derechos ofrecida por el Estado y procurar soluciones pacificadoras a favor de la armonía familiar ${ }^{7}$. La regulación legal de la mediación familiar se contiene en el título v de la ley n. ${ }^{\circ} 19.968$, denominado "De la mediación familiar", desde el artículo 103 al 114 inclusive. Esta normativa otorga un concepto de mediación (art. 103, ley 19.968), define los principios que rigen el proceso $^{8}$, señala las materias de mediación previa obligatoria, facultativa y prohibida (ibid., art. 106), establece normas para la derivación a mediación, designación de mediador (ibid., art. 107) y para la citación a la sesión inicial (ibid., art. 108), establece reglas especiales sobre la mediación en causas relativas al derecho de alimentos (ibid., art. 109), determina la duración del proceso (ibid., art. 110), el contenido del acta de mediación (ibid., art. 111), el costo del proceso (ibid., art. 114), y establece normas sobre el registro mediadores (ibid., art. 112).

El proceso de mediación transcurre en tres fases: la premediación, la mediación propiamente dicha y la posmediación ${ }^{9}$. La premediación se identifica con todas aquellas actividades -principalmente administrativas- orientadas a que pueda llevarse a cabo la mediación propiamente dicha. Dentro de estas actividades se encuentran, por ejemplo, la recepción de los antecedentes de las solicitudes de mediación y la entrega de información general a los usuarios acerca del servicio. En Chile, esta fase

6 Mera, A., "Mecanismos alternativos de solución de conflictos en América Latina. Diagnóstico y debate en un contexto de reformas", en Centro de Estudios de Justicia de las AmÉricAs, Aportes para un diálogo sobre el acceso a la justicia y reforma civil en América Latina, Santiago de Chile, CEJA, 2016, 408.

7 Biblioteca del Congreso Nacional de Chile, Historia de la Ley n. ${ }^{\circ}$ 19.968, 2004, 33; 755; 1039 disponible en [www.bcn.cl/historiadelaley/nc/historia-de-la-ley/5746/] [consultado el 7 de octubre de 2019].

8 "Durante todo el proceso de mediación, el mediador deberá velar por que se cumplan los siguientes principios en los términos que a continuación se señalan: (a) Igualdad: en virtud del cual el mediador se cerciorará de que los participantes se encuentren en igualdad de condiciones para adoptar acuerdos. Si no fuese así, propondrá o adoptará, en su caso, las medidas necesarias para que se obtenga ese equilibrio. De no ser ello posible, declarará terminada la mediación. (b) Voluntariedad: por el que los participantes podrán retirarse de la mediación en cualquier momento. Si en la primera sesión, o en cualquier otro momento durante el procedimiento, alguno de los participantes manifiesta su intención de no seguir adelante con la mediación, ésta se tendrá por terminada. (c) Confidencialidad: por el cual el mediador deberá guardar reserva de todo lo escuchado o visto durante el proceso de mediación y estará amparado por el secreto profesional [...] (d) Imparcialidad: lo que implica que los mediadores serán imparciales en relación con los participantes, debiendo abstenerse de promover actuaciones que comprometan dicha condición. Si tal imparcialidad se viere afectada por cualquier causa, deberán rechazar el caso, justificándose ante el juzgado que corresponda [...] (e) Interés superior del niño: por el cual, en el curso de la mediación, el mediador velará siempre por que se tome en consideración el interés superior del niño, niña o adolescente, en su caso, pudiendo citarlos sólo si su presencia es estrictamente indispensable para el desarrollo de la mediación. (f) Opiniones de terceros: en virtud del cual, el mediador velará por que se consideren las opiniones de los terceros que no hubieren sido citados a la audiencia, a quienes también podrá citar": Ibid., art. 105.

9 Suares, M., Mediando en sistemas familiares, Buenos Aires, Paidós, 2002, 245-276. 
generalmente no es abordada por el mediador, sino que se encomienda a funcionarios administrativos, y se destina, además, a realizar una evaluación socioeconómica de los usuarios para determinar si procede la gratuidad del servicio, y al ingreso de todos los antecedentes personales y socioeconómicos de los usuarios al Sistema Informático de Mediación Familiar (en adelante, Simef) ${ }^{10}$. La mediación propiamente dicha reúne al mediador y a las partes en conflicto en la sala de mediación. La primera labor que corresponde al mediador en esta etapa consiste en realizar un discurso de apertura para establecer las características principales de la mediación y de la modalidad de trabajo $^{11}$. En la mediación familiar de Chile, este discurso debe contener información acerca de la naturaleza y los objetivos de la mediación, los principios que la informan y el valor jurídico de los acuerdos que se pueden alcanzar (art. 107, ley 19.968). Otras labores profesionales que corresponden al mediador familiar en esta etapa son: resguardar los principios de la mediación familiar; favorecer la comunicación; gestionar las emociones, conducir el proceso hacia la búsqueda de acuerdos y redactar el acta de acuerdo o de cierre de la causa ${ }^{12}$. Los mediadores familiares de Chile deben resguardar durante todo el proceso de mediación los principios de: igualdad, voluntariedad, confidencialidad, imparcialidad, interés superior del niño y opiniones de terceros ${ }^{13}$. El mediador familiar también debe procurar actuar como facilitador de la comunicación entre las personas en conflicto ${ }^{14}$, ocupándose de establecer procesos de comunicación adecuados con cada uno de los participantes. Sin embargo, el Sistema Nacional de Mediación Familiar de Chile no cuenta con procedimientos de designación de intérpretes u otra alternativa institucionalizada para los casos en que los usuarios del servicio no hablan o no entienden el idioma del mediador ${ }^{15}$. Por ello, en la práctica, las solicitudes de mediación con las características antes señaladas son frustradas, esto es, finalizadas en el Simef, independiente de la voluntad de los usuarios de someter su disputa familiar a mediación. En consecuencia, esta brecha comunicacional y la falta de opciones para su tratamiento hacen que un segmento de la población chilena quede excluido de la justicia familiar colaborativa.

Las emociones están siempre presentes en los procesos de mediación. Generalmente la causa directa del bloqueo o entorpecimiento de la comunicación y colaboración entre las personas que asisten a mediación surge de la imposibilidad de éstas para gestionar adecuadamente sus emociones derivadas de los conflictos y crisis

10 Véase División Judicial, Unidad de Mediación, Bases tipo administrativas y técnicas generales, anexos y contrato tipo, para la contratación de servicios de mediación familiar, 2017, 45, disponible en [www.mediacionchile.cl/sitioumed/media/2018/01/Bases_Tipo_de_Licitacion_2018.pdf] [consultado el 7 de octubre de 2019]; Ley n. ${ }^{\circ}$ 19.968, artículos 103-114; 253-274.

11 Véase ibid., 44.

12 SuARes, M., Mediando en sistemas familiares, cit., 114-119.

13 Cfr. infra nota 8.

14 Escrivá-Ivars, J., Matrimonio y mediación familiar. Madrid, Rialp, 2001, 30.

15 Cfr. División Judicial, Unidad de Mediación, Bases tipo administrativas y técnicas generales, cit., 1-101; Ley n. ${ }^{\circ}$ 19.968, artículos 103-114. 
familiares ${ }^{16}$. Por ello, el mediador debe conducir las emociones de forma tal que no se conviertan en obstaculizadores de la comunicación y la colaboración o de la observancia de los principios que rigen al proceso de mediación familiar ${ }^{17}$.

En Chile, el artículo 103 de la ley n. ${ }^{\circ} 19.968$ explicita que la mediación familiar busca dar solución al conflicto y sus efectos mediante acuerdos. El mediador deberá, por tanto, conducir el proceso hacia la búsqueda de acuerdos, pero resguardando que sean las propias personas involucradas en el conflicto quienes tomen las decisiones conducentes a solucionarlo, según sus propios criterios y con base en sus propias necesidades ${ }^{18}$.

La mediación propiamente dicha puede terminar con la elaboración y firma de un acta de acuerdo sobre todas o alguna de las materias que llevaron a las partes a mediación, o con la frustración total o parcial de la causa en los casos que no fuere posible arribar a un consenso. En Chile es el mediador quien debe redactar el acta de acuerdo, tratándose del acta de mediación frustrada esta debe ser obtenida por aquel a través de Simef $^{19}$.

En la literatura internacional, la fase de la posmediación se relaciona exclusivamente con el monitoreo del cumplimiento de los acuerdos alcanzados por las parte $^{20}$. Sin embargo, en Chile los mediadores familiares también destinan esta etapa a otras actividades que derivan del resultado de la fase anterior, esto es, si se llegó o no a un acuerdo entre las partes. En el primer caso, la posmediación incluirá la remisión del acta de acuerdo al juez de familia respectivo para su homologación y el cierre de la causa en el Simef. Para esto último, el mediador debe informar en la plataforma si el juez de familia rechazó o aceptó, total o parcialmente, el acuerdo de las partes. En los casos en que no exista acuerdo, la posmediación incluirá el cierre de la causa en el Simef, donde el mediador deberá consignar el motivo por el cual ésta resultó frustrada ${ }^{21}$.

\section{B. El uso de tecnologías digitales en la mediación familiar}

Tanto en Chile como en el resto del mundo, hoy constituye un hecho notorio que las tecnologías digitales son parte de los centros de mediación familiar. Lo anterior, por ejemplo, a través de páginas virtuales en las que dichos centros informan sus servicios, teléfonos celulares con los que contactan a sus usuarios, o computadoras con las que el mediador redacta las actas de acuerdo o de cierre de las causas. En definitiva, se trata de tecnologías digitales que, si bien constituyen un apoyo para la prestación

16 SuAREs, M., Mediando en sistemas familiares, cit., 117-118.

17 Ibid., 114-119.

18 SuARes, M., Mediando en sistemas familiares, cit., 270-271.

19 División Judicial, Unidad de Mediación, Bases tipo administrativas y técnicas generales, cit., 44.

20 SuAREs, M., Mediando en sistemas familiares, cit., 275-276.

21 División Judicial, Unidad de Mediación, Bases tipo administrativas y técnicas generales, cit., 44. 
de estos servicios, no fueron creadas específicamente para la mediación, no alteran el procedimiento propiamente tal, ni aportan a este un valor añadido sustantivo ${ }^{22}$.

En Chile, las bases técnicas más recientes dictadas por la Unidad de Mediación ${ }^{23}$ para regular la provisión del Servicio Nacional de Mediación Familiar contienen exigencias básicas en cuanto a equipamiento computacional y conectividad para asegurar una adecuada gestión de las causas de mediación y el correcto funcionamiento de la plataforma digital Simef. Para los referidos fines, cada centro de mediación adjudicado en Chile debe disponer, a lo menos, de un computador o su equivalente en notebook $^{24}$ para el mediador y el asistente administrativo; una impresora multifuncional; una conexión a internet mínima de 50 megabytes; una conexión telefónica de red fija para efectuar y recibir llamadas locales, de larga distancia y celular, o equipos móviles según corresponda ${ }^{25}$. El Servicio Nacional de Mediación Familiar cuenta, además, con una página virtual en la que se informa a los usuarios acerca del servicio y una plataforma digital de agendamiento de horas de mediación en línea disponible a través de la misma página ${ }^{26}$.

En Europa, América del Norte y Oceanía se ha explorado el uso de tecnologías digitales, tales como internet y softwares de videoconferencia, para realizar sesiones de mediación familiar a distancia, con familias transfronterizas, transnacionales y aquellas ubicadas en zonas geográficas de difícil acceso ${ }^{27}$. También existen investigaciones que proponen realizar mediaciones familiares a distancia, mediante tec-

22 Poblet, M., Noriega, P., Suquet, J., Gabarró, S. y Redorta, J., “Tecnologías para la mediación en línea: estado del arte, usos y propuestas", en Casanovas, P., Magre, J. y Lauroba, M. (dirs.), Libro Blanco de la Mediación en Cataluña, Barcelona, Huygens, 2011, 949-950.

23 La Unidad de Mediación es la repartición técnica e interdisciplinaria del Ministerio de Justicia y Derechos Humanos, responsable de la administración del Sistema Nacional de Mediación Familiar. El objetivo principal de esta unidad es asegurar la provisión del servicio de mediación familiar, en cada uno de los territorios jurisdiccionales de los juzgados con competencia en asuntos de familia de todo el país.

24 El equipamiento computacional debe soportar un sistema operativo como Windows 7, OS-X Sierra, Linux u otro equivalente que sea compatible con el uso de navegadores Google Chrome o Mozilla Firefox en sus últimas versiones. Debe contar con un procesador de al menos 1, 6 / 2, $56 \mathrm{GHz}$, un disco duro mínimo de $250 \mathrm{~GB}$, memoria RAm de al menos 4 GB y un software de ofimática para visión de archivos Word, Excel y PDF.

25 Véase División Judicial, UnidAd de MEdiación, Bases tipo administrativas y técnicas generales, cit., 50-51.

26 Véase [www.mediacionchile.cl/sitioumed/] [consultado el 7 de octubre de 2019].

27 Barsky, A., "The Ethics of App-Assisted Family Mediation”, Conflict Resolution Quarterly, Association for Conflict Resolution, 34, 2016, 9-10; BAUGNIET, N., "La médiation familiale internationale", en BAUGniet, N., La médiation familiale: mode de règlement des conflits familiaux, Paris, De Boeck Supérieur, 2008, 77-78; Poblet, M., Noriega, P., Suquet, J., Gabarró, S. y Redorta, J., “Tecnologías para la mediación en línea: estado del arte, usos y propuestas", en CASANOVAS, P., MAgre, J. y LAURoBA, M. (dirs.), Libro Blanco de la Mediación en Cataluña, Barcelona, Huygens, 2011, 978-979; THE British Columbia Mediator Roster Society, Evaluation of the distance mediation project: Report on Phase II of the Technology-Assisted Family Mediation Project, 2010, 1-44, disponible en [http:// mediatebc.com/PDFs/1-2-Mediation-Services/Distance-Mediation-Project---Evaluation-Report.aspx] [consultado el 7 de octubre de 2019]. 
nologías digitales, en los conflictos donde existen antecedentes de violencia entre los usuarios. En estos casos, además de las ventajas espaciales y de velocidad, se plantea que dicha modalidad favorece el equilibrio de poder, reduce la hostilidad entre las partes y los peligros para la víctima ${ }^{28}$. En Catalunya las tecnologías digitales son utilizadas para gestionar las causas de mediación familiar, establecer diálogo con los usuarios, tramitar solicitudes de estos y habilitar los procesos de mediación familiar a distancia ${ }^{29}$. En México ${ }^{30}$, Nicaragua ${ }^{31}$ y Argentina -específicamente en la Provincia de Buenos Aires ${ }^{32}$ y Capital Federal ${ }^{33}$ - los organismos encargados de la administración de justicia han dispuesto plataformas digitales de acceso intranet para que los mediadores efectúen el registro y la gestión de las causas de mediación familiar en línea.

En definitiva, a partir de lo que venimos exponiendo podemos señalar que en la praxis nacional e internacional de la mediación familiar las tecnologías digitales se utilizan corrientemente para favorecer la conectividad entre los usuarios y el servicio, para facilitar labores de la premediación y la posmediación y para redactar las actas de acuerdo o de cierre de las causas en la mediación propiamente dicha.

\section{Nociones generales sobre la protección de la privacidad en Chile}

El vertiginoso desarrollo tecnológico/digital de las últimas décadas ha propiciado una masiva irrupción de tecnologías digitales en los diversos ámbitos del quehacer humano. Lo anterior, si bien ha traído considerables beneficios para los países en términos sociales y económicos, también ha provocado el surgimiento de nuevos retos en el ámbito mundial. Uno de estos desafíos se sitúa en el plano jurídico, y se refiere a la protección de la privacidad de las personas. Esta necesidad se explica por el hecho de que la mayor parte de la población mundial interactúa a diario con tecnologías digitales, esto sucede en espacios públicos y privados, pero no todos los individuos

28 Véanse Lavi, D., "Til Death Do Us Part: Online Mediation as an Answer to Divorce Cases Involving Violence", North Carolina Journal of Law \& Technology, University of North Carolina School of Law, 16, n. ${ }^{\circ}$ 2, 2015, 253-310; Rossi, F., Holtzworth-Munroe, A., Applegate, A., Beck, C., Adams, J. y HALE, D., "Shuttle and online mediation: a review of available research and implications for separating couples reporting intimate partner violence or abuse". Family Court Review, Association of Family and Conciliation Courts, 55, n. ${ }^{\circ} 3,2017,390-403$.

29 Poblet, M., Noriega, P., Suquet, J., Gabarró, S. y Redorta, J., “Tecnologías para la mediación en línea: estado del arte, usos y propuestas", cit., 978-979.

30 Véase Gaceta Oficial Distrito Federal, n. ${ }^{\circ}$ 1989, 2014, 22, disponible en [www.paot.org.mx/centro/ reglamentos/df/pdf/2014/123553GODF_19_11_2014.pdf] [consultado el 7 de octubre de 2019].

31 Véase Hernández, L., "Dirac crea plataforma digital para mejorar atención a los usuarios”, 2017, disponible en [www.poderjudicial.gob.ni/prensa/notas_prensa_detalle.asp?id_noticia=8405] [consultado el 7 de octubre de 2019].

32 Véase Sistema informático Mediare, disponible en [www.mediaciones-ba.org.ar/] [consultado el 7 de octubre de 2019].

33 Véase Sistema informático Mepre, disponible en [www.argentina.gob.ar/justicia/mediacion/mepre] [consultado el 7 de octubre de 2019]. 
involucrados son conscientes de dichas interacciones o de su alcance en términos de información ${ }^{34}$. En el contexto de la mediación familiar, plantear el uso de tecnologías digitales se torna complejo por la propia naturaleza de los conflictos familiares. Estos conflictos versan sobre aspectos de la vida privada e intimidad de los integrantes de una familia, incluyendo información relativa a los hijos que son niños o adolescentes. Por ello, para analizar las potenciales tecnologías digitales que podrían beneficiar las labores de los mediadores familiares de Chile, resulta necesario referirse a la normativa sobre protección de la vida privada y datos personales.

En Chile, la vida privada es un derecho fundamental cuya protección constitucional versa desde 1980. La protección de los datos personales se consagró como un derecho fundamental dentro de la Constitución, el día 16 de junio de 2018 mediante

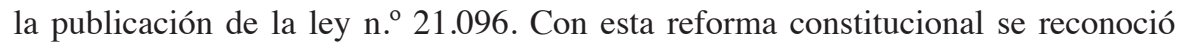
a los datos personales como parte importante de la identidad de las personas y se materializó la emergencia de otorgarles una protección expedita y ágil frente a las posibles vulneraciones asociadas a la expansión de las tecnologías digitales ${ }^{35}$. Según la Constitución, "el tratamiento y protección de estos datos se efectuará en la forma y [las] condiciones que determine la ley" ${ }^{36}$. La ley n. ${ }^{\circ} 19.628$ sobre protección de la vida privada, publicada el día 28 de agosto de 1999, reguló el tratamiento de datos personales en registros o bancos de datos por parte de terceros. Actualmente la agenda legislativa nacional tiene en curso un proyecto de ley que busca modificar la ley n. ${ }^{\circ} 19.628^{[37]}$. No obstante, esta es la única ley vigente sobre protección de la vida privada en el ámbito civil. Para efectos de esta ley, el tratamiento de datos es

Cualquier operación o complejo de operaciones o procedimientos técnicos, de carácter automatizado o no, que permitan recolectar, almacenar, grabar, organizar, elaborar, seleccionar, extraer, confrontar, interconectar, disociar, comunicar, ceder, transferir, transmitir o cancelar datos de carácter personal, o utilizarlos en cualquier otra forma (art. 2, lit. o, ley 19.628).

La ley define el registro o banco de datos como "el conjunto organizado de datos de carácter personal sea automatizado o no y cualquiera sea la forma o modalidad de su creación u organización, que permita relacionar los datos entre sí, así como realizar todo tipo de tratamiento de datos" (art. $2^{\circ}$, lit. m, ibid.). Como se ve, la creación del banco de datos y el respectivo tratamiento de estos puede realizarse por

34 Organización para la Cooperación y el Desarrollo Económicos, Perspectivas de la ocde sobre la economía digital 2017, Ciudad de México, ocDE, 2017, 24; 104.

35 Biblioteca del Congreso Nacional de Chile, Historia de la Ley n. ${ }^{\circ} 21.096,2018,32 ; 78 ; 89 ; 132$, disponible en [www.bcn.cl/historiadelaley/nc/historia-de-la-ley/7551/] [consultado el 7 de octubre de 2019].

36 Constitución Política de la República de Chile, artículo 19, número 4.

37 Véanse boletines n. ${ }^{\circ} 11.144-07$ y n. ${ }^{\circ} 11.092-07$, refundidos, disponibles en [www.camara.cl/pley/ pley_detalle.aspx?prmID=11661\&prmBoletin=11144-07] [consultado el 7 de octubre de 2019]. 
medio de tecnologías o procedimientos manuales. La ley contempla asimismo una definición abierta con respecto a las acciones que serían constitutivas de un tratamiento de datos, pues si a partir de cualquier operación o complejo de operaciones o procedimientos técnicos es posible utilizar los datos personales de alguna manera se cumpliría el supuesto contenido en la ley.

Conforme a la ley en comento, los datos de carácter personal o datos personales son "los relativos a cualquier información concerniente a personas naturales, identificadas o identificables" (art. 2, lit. f, ibid.). De lo anterior se desprende que, si bien la afectación del derecho a la protección de datos personales puede ser provocado por terceros, sean estos personas jurídicas o naturales, de la protección a este derecho solo puede recaer en datos de personas naturales, excluyendo en este caso a las personas jurídicas. Los datos sensibles son definidos como

aquellos datos personales que se refieren a las características físicas o morales de las personas o a hechos o circunstancias de su vida privada o intimidad, tales como los hábitos personales, el origen racial, las ideologías y opiniones políticas, las creencias o convicciones religiosas, los estados de salud físicos o psíquicos y la vida sexual (art. 2, lit. f, ibid.).

En este caso, el legislador no define los hechos o circunstancias que han de considerarse parte de la vida privada o intimidad de la persona, sino que otorga algunos ejemplos. Con ello, el legislador reconoce que los límites de lo público y lo privado son variables y entrega a la doctrina y a la jurisprudencia la responsabilidad de esclarecerlos. Hay autores que postulan que la esfera íntima y personal del individuo debiese entenderse compuesta por: el aspecto físico corporal, que incluiría la imagen, la constitución y los defectos físicos; el perfil psíquico, que incluiría el carácter y las anomalías psiquiátricas o psicológicas; lo afectivo, que incluiría los sentimientos y afectos; la situación material, que incluiría las condiciones económicas y el nivel de vida; el comportamiento y las relaciones, que incluirían el ámbito amoroso, familiar y profesional. Para otros, las circunstancias de la vida íntima de la persona serían las costumbres, el modo de vivir, las desgracias personales, la situación económica, las divergencias conyugales, la educación de los hijos, las amistades, enemistades, estados mentales, comportamientos en las relaciones sociales, los orígenes familiares y los aspectos no públicos de la vida profesional ${ }^{38}$.

Según la ley en comento, el tratamiento de datos personales "sólo puede efectuarse cuando esta ley u otras disposiciones legales lo autoricen o el titular consienta expresamente en ello" (art. 4, inc. 1, ibid.). En este último caso, "La autorización debe constar por escrito" (art. 4, inc. 3, ibid.).

En cuanto al tratamiento de datos sensibles, la ley dispone que

38 Novoa, E., Derecho a la vida privada y libertad de información: un conflicto de derechos, Buenos Aires, Siglo XxI, 2001, 38-42. 
No pueden ser objeto de tratamiento los datos sensibles, salvo cuando la ley lo autorice, exista consentimiento del titular o sean datos necesarios para la determinación u otorgamiento de beneficios de salud que correspondan a sus titulares (art. 10, ibid.).

La ley establece que "Los datos personales deben utilizarse sólo para los fines para los cuales hubieren sido recolectados [...]" (art. 9, inc. 1, ibid.), esto es lo que en doctrina se denomina "principio de finalidad" 39.

Esta ley también considera casos en que los datos personales pueden ser objeto de tratamiento por parte de terceros sin requerir autorización de su titular. En este sentido se señala que

No requiere autorización el tratamiento de datos personales que provengan o que se recolecten de fuentes accesibles al público, cuando sean de carácter económico, financiero, bancario o comercial, se contengan en listados relativos a una categoría de personas que se limiten a indicar antecedentes tales como la pertenencia del individuo a ese grupo, su profesión o actividad, sus títulos educativos, dirección o fecha de nacimiento, o sean necesarios para comunicaciones comerciales de respuesta directa o comercialización o venta directa de bienes o servicios. Tampoco requerirá de esta autorización el tratamiento de datos personales que realicen personas jurídicas privadas para el uso exclusivo suyo, de sus asociados y de las entidades a que están afiliadas, con fines estadísticos, de tarificación u otros de beneficio general de aquellos (art. 4, inc. 5, ibid.).

Para efectos de esta ley se entiende por "fuentes accesibles al público" "los registros o recopilaciones de datos personales, públicos o privados, de acceso no restringido o reservado a los solicitantes" y por "dato estadístico" "el dato que, en su origen, o como consecuencia de su tratamiento, no puede ser asociado a un titular identificado o identificable" (art. 2, lit. e, ibid.).

\section{Resultados de la investigación}

Nuestro corpus documental estuvo conformado por ocho artículos de investigación de autores internacionales ${ }^{40}$ y cinco páginas virtuales ${ }^{41}$, de estos documentos extrajimos doce tecnologías digitales que analizamos a continuación:

39 Cfr. Viollier, P., El estado de la protección de datos personales en Chile, Santiago de Chile, Derechos Digitales, 2017, 22.

40 Véanse Bellucci, E., "Software Developed for Use in Family Mediation-AssetDivider", Ceur-WS, 482, 2009, 55-66; BelluCCI, E. y ZeleZNiKow, J., "Developing negotiation decision support systems that support mediators: A case study of the Family Winner system", Artificial Intelligence and Law, Springer, 13, 2009, 233-271; Bellucci, E., Macfarlane, D. y Zeleznikow, J., "How Information Technology Can Support Family Law and Mediation", en Abramowicz, W., Tolksdorf, R. y WĘCEL, K. (eds.), Business Information Systems Workshops. BIs 2010. Lecture Notes in Business Information 


\section{A. Traduseñas}

Aplicación móvil chilena para la traducción de palabras y frases desde el español al lenguaje de señas chileno y viceversa, permite que personas con discapacidad auditiva puedan comunicarse en tiempo real con personas oyentes. Traduseñas debe ser instalado en un teléfono celular inteligente, pero no requiere conexión a internet. La aplicación puede ser utilizada secuencialmente por cada persona sorda y oyente a través de un mismo dispositivo móvil.

Traduseñas podría aportar al mediador familiar en la labor de favorecer la comunicación entre las personas sordas y oyentes; se resguardan de este modo los principios de igualdad y de participación de terceros, en todos aquellos casos en que personas cuyo único medio de expresión sea el lenguaje de señas soliciten participar o ser usuarios del servicio.

El título v de la ley n. ${ }^{\circ} 19.968$ no contiene normas referentes a los medios o herramientas que el mediador familiar deba o pueda utilizar para el cumplimiento de sus labores durante la mediación propiamente dicha, lo cual hace posible la incorporación de Traduseñas a esta etapa. Las características de esta tecnología no se oponen a ninguno de los principios legales de la mediación familiar, ni a las demás normas contenidas en el referido título, y es, por tanto, apta según la ley n. ${ }^{\circ} 19.968$.

Por la naturaleza de las materias de familia, es esperable que en la comunicación que pueda establecer el mediador con los usuarios a través de esta tecnología puedan incluirse antecedentes que a la luz de ley n. ${ }^{\circ} 19.628$ calificarían como datos personales o sensibles, los que con el uso de Traduseñas estarían siendo objeto de tratamiento conforme a la referida ley. Sin embargo, en este contexto la tecnología no funciona con información extraída de un banco de datos o un registro tal como lo define esta ley, y su solo uso tampoco da lugar a su creación. Por ello, en la mediación familiar la tecnología sería apta conforme a la ley n. ${ }^{\circ} 19.628$.

Processing, Berlin, Springer, 2010, 55-66; Gervasi, O., Franzoni, V., Riganelli, M. y Tasso, S., "Automating facial emotion recognition", Web Intelligence, Ios Press, 17, 2019, 17-27; Noroozi, F., Escalera, S., Njegus, A. y Anbarjafari, G., "Audio-Visual Emotion Recognition in Video Clips", IEEE Transactions on Affective Computing archive, IEE Xplore, 10, 2019, 60-75; Mohanmod, S. y Muнammad, G., "Emotion recognition using deep learning approach from audio-visual emotional big data", Information Fusion, 49, 2019, 69-78; Zeleznikow, J., y Bellucci, E., "Family Winner: Integrating Game Theory and Heuristics to Provide Negotiation Support", en Bourcier, D. (ed.), Legal Knowledge and Information Systems, JURIX 2003: The Sixteenth Annual Conference. Amsterdam, Ios press, 2003, 22-24; Zeleznikow, J., Bellucci, E., Schild, U. y Mackenzie, G., "Bargaining in the shadow of the Law - using utility functions to support legal negotiation", en ICAIL 2007: Proceedings of the 11th International Conference on Artificial Intelligence and Law, Association for Computing Machinery. New York, ACM, 2007, 237-246.

41 Véanse [www.dw.com/es/mivos-una-aplicaci\%C3\%B3n-revolucionaria-para-sordos/av-42523928]; [www.behance.net/gallery/75582063/TraduSenas-Chile]; [http://mixedemotions.insight-centre.org/]; [https://play.google.com/store/apps/details?id=com.google.android.apps.translate\&hl=es]; [www.di vorciofacil.cl/calculadora-pension-de-alimentos/]. 


\section{B. Google Translate}

Aplicación móvil que permite traducir y entender más de cien idiomas, ya sea a través de textos, imágenes, audios o conversaciones en tiempo real. Google Translate debe ser instalado en un teléfono celular inteligente, el cual además debe tener conexión a internet para la traducción de conversaciones, audios e imágenes. La aplicación puede ser utilizada secuencialmente por cada emisor en un mismo dispositivo móvil.

Google Translate podría aportar al mediador familiar en la labor de favorecer la comunicación entre hablantes de distintos idiomas; se resguardan con ello los principios de igualdad y de participación de terceros, en todos aquellos casos en que personas que no entiendan o no puedan expresarse en español soliciten participar o ser usuarios del servicio.

El título v de la ley n. ${ }^{\circ} 19.968$ no contiene normas referentes a los medios o herramientas que el mediador familiar deba o pueda utilizar para el cumplimiento de sus labores durante la mediación propiamente dicha, lo cual hace posible la incorporación de Google Translate a esta etapa. Las características de esta tecnología no se oponen a ninguno de los principios legales de la mediación familiar, ni a las demás normas contenidas en el referido título, y es, por tanto, apta según la ley n. ${ }^{\circ} 19.968$.

Por la naturaleza de las materias de familia, es de esperarse que en la comunicación que pueda establecer el mediador con los usuarios a través de esta tecnología se incluyan antecedentes que a la luz de ley n.$^{\circ} 19.628$ calificarían como datos personales o sensibles, los cuales con el uso de Google Translate estarían siendo objeto de tratamiento conforme a la referida ley. Sin embargo, en este contexto la tecnología no funciona con información extraída de un banco de datos o un registro tal como lo define esta ley, y su solo uso tampoco da lugar a su creación. Por ello, en la mediación familiar la tecnología sería apta acuerdo a la ley n. ${ }^{\circ} 19.628$.

\section{AffdexMe}

Software de código abierto que permite procesar y analizar, en tiempo real, las expresiones faciales, identificando a partir de ellas, seis emociones básicas: ira, desprecio, miedo, disgusto, tristeza y alegría. AffdexMe puede ser instalada en un teléfono inteligente, tableta o computadora, funciona a través de la cámara incorporada en el respectivo dispositivo y no requiere conexión a internet. En la pantalla de cada dispositivo se visualizará en tiempo real el informe de métricas, que describirá las expresiones faciales y las emociones. Para ejecutar esta tecnología, basta una persona, quien podrá usarla sobre sí misma a través de la cámara frontal o sobre terceras personas, mediante la cámara trasera del dispositivo.

AffdexMe podría aportar al mediador familiar en la labor de identificar las emociones propias y ajenas tras las expresiones faciales, de manera objetiva y con altos niveles de precisión, aportando con ello a la gestión de las emociones. Esta información objetiva serviría asimismo para resguardar el principio de imparcialidad y para favorecer la comunicación, ya que a través de esta el mediador podría conocer 
cómo expresa sus emociones a cada usuario y, además, disminuir la concurrencia de interpretaciones equívocas respecto de las expresiones faciales.

El título v de la ley n..$^{\circ} 19.968$, no contiene normas referentes a los medios o herramientas que el mediador familiar deba o pueda utilizar para el cumplimiento de sus labores durante la mediación propiamente dicha, lo cual hace posible la incorporación de AffdexMe a esta etapa. Las características de esta tecnología no se oponen a ninguno de los principios legales de la mediación familiar, ni a las demás normas contenidas en el referido título, y es, por tanto, apta según la ley n. ${ }^{\circ} 19.968$.

Para efectos de la ley n. ${ }^{\circ} 19.628$, la captura gráfica y el análisis del rostro de terceras personas y sus expresiones faciales corresponderían a un tratamiento de datos sensibles. Sin embargo, en este contexto la tecnología no funciona con información extraída de un banco de datos o un registro tal como lo define esta ley, y su solo uso tampoco da lugar a su creación. Por ello, en la mediación familiar la tecnología sería apta según la ley n. ${ }^{\circ} 19.628$.

\section{MixedEmotions}

Software de código abierto para la extracción y el análisis de emociones multimodales y multilingües, contenidas en audios, textos o expresiones faciales video grabadas. Para acceder a MixedEmotions se requiere una computadora con conexión a internet. La extracción y el análisis de emociones no se hacen en tiempo real, sino que se efectúan a partir de los audios, textos o videos que el usuario sube a la plataforma. Los videos pueden tener un tamaño máximo de $60 \mathrm{MB}$ y los rostros deben tener una altura mínima de 50 pixeles. Para el audio y texto no se señalan requerimientos específicos. Los registros audiovisuales no pueden analizarse de forma conjunta, el audio y las expresiones faciales videograbadas se analizan separadamente. Se debe contar, por tanto, con un dispositivo que permita grabar audio o video o procesar texto digital. Para la ejecución de la plataforma no se requiere más de una persona, pero ésta debe tener nociones básicas de inglés.

MixedEmotions podría aportar al mediador familiar en la labor de identificar las emociones propias y ajenas tras las expresiones faciales, de manera objetiva y con altos niveles de precisión, aportando con ello a la gestión de las emociones. Esta información objetiva serviría asimismo para resguardar el principio de imparcialidad y para favorecer la comunicación, ya que a través de esta el mediador podría conocer cómo expresa sus emociones a cada usuario y, además, disminuir la concurrencia de interpretaciones equívocas respecto de las expresiones faciales.

El título v de la ley n. ${ }^{\circ} 19.968$ no contiene normas referentes a los medios o herramientas que el mediador familiar deba o pueda utilizar para el cumplimiento de sus labores durante la mediación propiamente dicha, lo cual hace posible la incorporación de Mixedemotions a esta etapa. Las características de esta tecnología no se oponen a ninguno de los principios legales de la mediación familiar, ni a las demás normas contenidas en el referido título, y es, por tanto, apta según la ley n. ${ }^{\circ} 19.968$. 
Para efectos de la ley n. ${ }^{\circ} 19.628$, si a través de esta tecnología se procesan documentos, imágenes o audios referidos a datos personales o sensibles de los usuarios, esto correspondería a un tratamiento de datos personales o sensibles. Sin embargo, en este contexto la tecnología no funciona con información extraída de un banco de datos o un registro tal como lo define esta ley, y su solo uso tampoco da lugar a su creación. Por ello, en la mediación familiar la tecnología sería apta según la ley n. ${ }^{\circ}$ 19.628.

\section{E. MIVOS}

Software chileno para la traducción del lenguaje de señas a audio, y viceversa. Interpreta imágenes en tiempo real y las convierte en sonido; al mismo tiempo, cuando una persona habla, produce una seña virtual para las personas no oyentes. MIVos puede ser instalado en un teléfono celular inteligente o computadora y no requiere conexión a internet. La tecnología puede ser utilizada secuencialmente por cada persona sorda y oyente en un mismo dispositivo.

MIVos podría aportar al mediador familiar en la labor de favorecer la comunicación entre las personas sordas y las oyentes; se resguardan de este modo los principios de igualdad y de participación de terceros, en todos aquellos casos en que personas cuyo único medio de expresión sea el lenguaje de señas soliciten participar o ser usuarios del servicio.

El título v de la ley n. ${ }^{\circ} 19.968$ no contiene normas referentes a los medios o herramientas que el mediador familiar deba o pueda utilizar para el cumplimiento de sus labores durante la mediación propiamente dicha, lo cual hace posible la incorporación de mivos a esta etapa. Las características de esta tecnología no se oponen a ninguno de los principios legales de la mediación familiar, ni a las demás normas contenidas en el referido título, y es, por tanto, apta según la ley n. ${ }^{\circ} 19.968$.

Por la naturaleza de las materias de familia, es esperable que en la comunicación que pueda establecer el mediador con los usuarios a través de esta tecnología puedan incluirse antecedentes que a la luz de ley n. ${ }^{\circ} 19.628$ calificarían como datos personales o sensibles, los que con el uso de mivos estarían siendo objeto de tratamiento conforme a la referida ley. Sin embargo, en este contexto la tecnología no funciona con información extraída de un banco de datos o un registro tal como lo define esta ley, y su solo uso tampoco da lugar a su creación. Por ello, en la mediación familiar la tecnología sería apta según la ley n. ${ }^{\circ} 19.628$.

\section{F. Audiovisual emotion recognition}

Software de reconocimiento de emociones multimodales, capaz de identificar en registros audiovisuales las emociones de ira, disgusto, miedo, felicidad, tristeza y sorpresa. El sistema de reconocimiento de emociones audiovisuales debe ser instalado en una computadora y no requiere conexión a internet. La extracción y el análisis de emociones no se hacen en tiempo real, sino que se efectúan a partir del registro audiovisual aportado por el usuario. Se debe contar, por tanto, con un dispositivo que 
permita grabar material audiovisual. Para la ejecución de la plataforma no se requiere más de una persona, pero ésta debe tener nociones básicas de inglés.

El sistema de reconocimiento de emociones audiovisuales podría aportar al mediador familiar en la labor de identificar las emociones propias y ajenas tras las expresiones faciales, de manera objetiva y con altos niveles de precisión, aportando con ello a la gestión de las emociones. Esta información objetiva serviría asimismo para resguardar el principio de imparcialidad y para favorecer la comunicación, ya que, a través de esta, el mediador podría conocer cómo expresa sus emociones a cada usuario y, además, disminuir la concurrencia de interpretaciones equívocas respecto de las expresiones faciales.

El título v de la ley n. ${ }^{\circ} 19.968$ no contiene normas referentes a los medios o herramientas que el mediador familiar deba o pueda utilizar para el cumplimiento de sus labores durante la mediación propiamente dicha, lo cual hace posible la incorporación de audiovisual emotion recognition a esta etapa. Las características de esta tecnología no se oponen a ninguno de los principios legales de la mediación familiar, ni a las demás normas contenidas en el referido título, y es, por tanto, apta según la ley n. ${ }^{\circ} 19.968$.

Para efectos de la ley n. ${ }^{\circ} 19.628$, si se procesa registros audiovisuales que incluyan datos personales o sensibles de los usuarios, esto correspondería a un tratamiento de estos. Sin embargo, en este contexto la tecnología no funciona con información extraída de un banco de datos o un registro tal como lo define esta ley, y su solo uso tampoco da lugar a su creación. Por ello, en la mediación familiar la tecnología sería apta según la ley n. ${ }^{\circ} 19.628$.

\section{G. EmEx2}

Software diseñado para automatizar la detección de emociones en expresiones faciales adquiridas a través de una cámara incorporada. Este software puede identificar las emociones de ira, disgusto, miedo, felicidad, tristeza y sorpresa. EmEx2 debe ser instalado en una computadora con cámara incorporada, y no requiere conexión a internet. La extracción y el análisis de emociones se hacen en tiempo real. Para la ejecución del software no se requiere más de una persona, pero ésta debe tener nociones básicas de inglés.

EmEx2 podría aportar al mediador familiar en la labor de identificar las emociones propias y ajenas tras las expresiones faciales, de manera objetiva y con altos niveles de precisión, aportando con ello a la gestión de las emociones. Esta información objetiva serviría asimismo para resguardar el principio de imparcialidad y para favorecer la comunicación, ya que a través de esta el mediador podría conocer cómo expresa sus emociones a cada usuario y, además, disminuir la concurrencia de interpretaciones equívocas respecto de las expresiones faciales.

El título v de la ley n. ${ }^{\circ} 19.968$, no contiene normas referentes a los medios o herramientas que el mediador familiar deba o pueda utilizar para el cumplimiento de 
sus labores durante la mediación propiamente dicha, lo cual hace posible la incorporación de EmEx2 a esta etapa. Las características de esta tecnología no se oponen a ninguno de los principios legales de la mediación familiar, ni a las demás normas contenidas en el referido título, y es, por tanto, apta según la ley n. ${ }^{\circ} 19.968$.

Para efectos de la ley n. ${ }^{\circ} 19.628$, si se analizan el rostro y las expresiones faciales de los usuarios, esto correspondería a un tratamiento de datos sensibles, según esta ley. Sin embargo, en este contexto la tecnología no funciona con información extraída de un banco de datos o un registro tal como lo define esta ley, y su solo uso tampoco da lugar a su creación. Por ello, en la mediación familiar la tecnología sería apta según la ley n. ${ }^{\circ} 19.628$.

\section{H. DEUS}

Software de apoyo para los procesos de negociación familiares relativos a distribución de bienes u otras cuestiones valorables en dinero. Entrega información gráfica acerca de los problemas en disputa, las ofertas de cada parte y del nivel de cercanía (o lejanía) en que se encuentran los negociadores para llegar a un acuerdo. Para esto último, DEus considera los objetivos monetarios de cada parte y los intereses que los sustentan. DEus debe ser instalado en una computadora, pero no requiere conexión a internet. Para la ejecución del software no se requiere más de una persona, pero ésta debe tener nociones básicas de inglés.

DEUS podría apoyar las intervenciones del mediador familiar a través de representaciones gráficas objetivas que servirían para sustentar la determinación del conflicto, la búsqueda de opciones y el análisis de posibles soluciones, especialmente en los casos relativos al derecho de alimentos o liquidación de régimen de bienes por divorcio o separación judicial. Todo lo anterior ayudaría al mediador familiar a conducir el proceso hacia la búsqueda de acuerdos.

El título v de la ley n. 19.968 no contiene normas referentes a los medios o herramientas que el mediador familiar deba o pueda utilizar para el cumplimiento de sus labores durante la mediación propiamente dicha, lo cual hace posible la incorporación de DEUS a esta etapa. Las características de esta tecnología no se oponen a ninguno de los principios legales de la mediación familiar, ni a las demás normas contenidas en el referido título, y es, por tanto, apta según la ley n. ${ }^{\circ} 19.968$.

Para efectos de la ley n. ${ }^{\circ} 19.628$, el procesamiento de la información relativa a los objetivos e intereses personales de cada parte en relación con los conflictos por derecho de alimentos o liquidación de régimen de bienes, así como la información de las respectivas ofertas o concesiones ofrecidas por cada parte, podría constituir un tratamiento de datos personales o sensibles. Sin embargo, en este contexto la tecnología no funciona con información extraída de un banco de datos o un registro tal como lo define esta ley, y su solo uso tampoco da lugar a su creación. Por ello, en la mediación familiar la tecnología sería apta según la ley n. 19.628. 


\section{AdjustWinner, FamilyWinner, y Asset Divider}

Estas tres tecnologías son softwares de apoyo para los procesos de toma de decisiones en la distribución de bienes, los que, a través de una manipulación matemática de preferencias numéricas, otorgan una solución al conflicto negociado. AdjustWinner, FamilyWinner y Asset Divider deben ser instalados en una computadora, pero no requieren conexión a internet. Para la ejecución de cada software no se requiere más de una persona, pero ésta debe tener nociones básicas de inglés.

AdjustWinner, FamilyWinner y Asset Divider otorgarían opciones objetivas de solución a los conflictos de distribución de bienes, las que el mediador podría sugerir a los usuarios, máxime en aquellos casos en que la creatividad de estos se hubiese agotado sin llegar a un consenso. Lo anterior podría ayudar al mediador familiar a conducir el proceso hacia la búsqueda de acuerdos.

El título v de la ley n. ${ }^{\circ} 19.968$ no contiene normas referentes a los medios o herramientas que el mediador familiar deba o pueda utilizar para el cumplimiento de sus labores durante la mediación propiamente dicha, lo cual hace posible la incorporación de AdjustWinner, FamilyWinner y Asset Divider a esta etapa. Las características de estas tecnologías no se oponen a ninguno de los principios legales de la mediación familiar, ni a las demás normas contenidas en el referido título, y son, por tanto, aptas según la ley n. ${ }^{\circ} 19.968$.

Para efectos de la ley n. ${ }^{\circ} 19.628$, el procesamiento de la información relativa a las preferencias personales de cada parte en relación con los conflictos familiares en disputa podría constituir un tratamiento de datos personales o sensibles. Sin embargo, en este contexto las tecnologías no funcionan con información extraída de un banco de datos o un registro tal como lo define esta ley, y su solo uso tampoco da lugar a su creación. Por ello, en la mediación familiar estas tecnologías serían aptas según la ley n. ${ }^{\circ} 19.628$.

\section{J. Calculadora de pensión de alimentos}

Software chileno, de acceso en línea, para calcular el monto de una pensión de alimentos, que funciona a través de la distribución proporcional de los gastos del hijo en relación con las facultades económicas de cada padre. Para acceder a la Calculadora de pensión de alimentos es necesario contar con una computadora, tableta o celular inteligente, con conexión a internet. Para la ejecución de este software no se requiere más de una persona.

La Calculadora de pensión de alimentos podría apoyar al mediador familiar en el establecimiento de un monto de referencia de dicho derecho, en los casos en que los padres deseasen considerar como criterio de acuerdo la distribución proporcional de gastos con base en sus facultades económicas declaradas. Lo anterior ayudaría al mediador familiar a conducir el proceso hacia la búsqueda de acuerdos. 
El título v de la ley n. ${ }^{\circ} 19.968$ no contiene normas referentes a los medios o herramientas que el mediador familiar deba o pueda utilizar para el cumplimiento de sus labores durante la mediación propiamente dicha, lo cual hace posible la incorporación de la Calculadora de pensión de alimentos a esta etapa. Las características de esta tecnología no se oponen a ninguno de los principios legales de la mediación familiar, ni a las demás normas contenidas en el referido título, y es, por tanto, apta según la ley n. ${ }^{\circ} 19.968$.

Para efectos de la ley n. ${ }^{\circ} 19.628$, el procesamiento de la información relativa a la capacidad económica de cada padre y los gastos y necesidades pecuniarias de sus respectivos hijos menores de edad podría constituir un tratamiento de datos personales o sensibles. Sin embargo, en este contexto la tecnología no funciona con información extraída de un banco de datos o un registro tal como lo define esta ley, y su solo uso tampoco da lugar a su creación.

\section{Discusión}

De nuestros resultados se concluye que existen doce tecnologías digitales mediante las cuales se podría contribuir al desarrollo de labores distintas de la redacción de actas en la mediación propiamente dicha, en armonía con las leyes n. ${ }^{\text {os }} 19.968$ y 19.628 de la legislación chilena. Por lo anterior, la hipótesis que sostuvimos al iniciar este trabajo resulta confirmada. Esta información es relevante, en tanto permite conocer que el uso restringido de las tecnologías digitales en la mediación familiar de Chile no se debe a la falta de tecnologías con el potencial de contribuir al proceso, o a la existencia de prohibiciones normativas. No obstante, la información antes señalada no resulta suficiente para que el mediador familiar pueda discernir acerca de la conveniencia de utilizar una determinada tecnología en la mediación propiamente dicha.

En este sentido, creemos que la información anterior requiere complementarse con otros aspectos. Uno de los factores adicionales que consideramos necesario analizar son las características de las tecnologías en relación con los presupuestos teóricos en los cuales se funda el proceso. Con esto nos referimos a la necesidad de evaluar si con el uso de una determinada tecnología podría arriesgarse más allá de lo razonable la observancia de algún supuesto teórico de la mediación no previsto normativamente. Así, de las doce tecnologías digitales analizadas, estimamos que AffdexMe y EmEx2 son las que presentan un mayor riesgo de transgredir la teoría de la mediación, dadas sus características de funcionamiento. Estas tecnologías operan en tiempo real y no permiten guardar registro de las emociones informadas, de manera tal que si el mediador familiar quisiera obtener el beneficio que estas ofrecen -consistente en conocer las emociones concurrentes en el proceso- mientras transcurriera la respectiva sesión tendría que visualizar de manera constante la pantalla del dispositivo en que operase el software. Sin embargo, creemos que este ejercicio exigiría suma diligencia del mediador, pues de lo contrario se afectarían la escucha y la observación activas que debe efectuar durante todo el proceso, así como la secuencia de construcción de confianza 
con los usuarios. Lo anterior, debido a que el desvío reiterativo de la mirada hacia un elemento tecnológico que en ningún momento interactuaría de forma activa con los usuarios podría ser interpretado por éstos como una falta de interés o de atención por parte del profesional. Por ello, si el mediador familiar no es capaz de prever tales dificultades, junto con los mecanismos adecuados para una solución, o la manera de enfrentar sus consecuencias una vez acaecidas, resultaría totalmente desaconsejable el uso de las mencionadas tecnologías, pues con ello no se aportaría ningún beneficio al proceso de mediación, sino que, por el contrario, solo se perjudicaría su adecuada observancia. En cambio, las otras tecnologías orientadas a la identificación de emociones, a saber: audiovisual emotion recognition y MixedEmotions, al funcionar con base en registros audiovisuales previos, no generan los riesgos antes mencionados dentro del proceso de mediación. Ahora bien. Tratándose de las otras tecnologías analizadas, a saber: Traduseñas, MIvos, Google Translate, DEus, AdjustWinner, Family Winner, Asset Divider y la Calculadora de pensión de alimentos, todas ellas involucran al usuario para su funcionamiento, pues requieren información que debe ser proporcionada por ellos, con lo cual se disminuye considerablemente el riesgo de que estos puedan sentirse desplazados o no considerados por el mediador al momento de su uso. Con todo, lo anterior no significa que el uso de audiovisual emotion recognition, MixedEmotions Traduseñas, MIVos, Google Translate, DEus, AdjustWinner, FamilyWinner, Asset Divider y la Calculadora de pensión de alimentos esté exento de complicaciones. Pues el hecho de que una tecnología ofrezca potenciales beneficios para el mediador con características compatibles con las leyes n. ${ }^{\text {os }} 19.968$ y 19.628 y los presupuestos teóricos de la mediación no es lo que determina la utilidad final de ella. También será determinante la manera en que el mediador emplee cada tecnología en la práctica. Así, por ejemplo, si un mediador utiliza alguna de las diez tecnologías en comento, explicando únicamente a una de las personas en conflicto los fines de su utilización, o favoreciendo exclusivamente a una de ellas con sus utilidades, afectaría los principios legales de igualdad o imparcialidad del proceso, y probablemente la secuencia de construcción de confianza con los usuarios. De la misma forma, si un mediador no conoce previamente el funcionamiento de alguna de estas tecnologías o no confía en ellas, y aun así decide incorporarla, podría desatender el proceso entero en función de este elemento. De esta manera, evidentemente se perderían todas las potencialidades de la tecnología digital, por esto no se debe exaltar innecesariamente el rol de las tecnologías digitales, pues la responsabilidad del mediador será siempre un factor trascendental. Por ello, el mediador que se enfrenta a una tecnología con potenciales beneficios para sus labores requiere además autoevaluar sus propias características personales y profesionales junto a las particularidades del caso en concreto para finalmente determinar si podría hacer uso de dicha tecnología sin afectar su desempeño global.

Las implicancias éticas que podrían derivarse del uso de cada tecnología es otro de los aspectos que debiesen ser considerados. Esto porque las tecnologías analizadas -las que probablemente dentro de poco aumenten en número y variedad-podrían 
ser utilizadas por los mediadores de Chile para tratar cuestiones relativas a la vida privada de los integrantes de una familia, incluyendo los niños o adolescentes. Por ello se debe destacar que aun cuando la ley n. ${ }^{\circ} 19.968$ no regule el uso de tecnologías digitales y la ley n. ${ }^{\circ} 19.628$ solo se refiera al tratamiento de datos personales en registros o bancos de datos que difícilmente podrían requerirse para el uso de una tecnología en mediación, no puede soslayarse que con el uso de las tecnologías digitales se puede aumentar el riesgo de que se presenten vulneraciones a los derechos fundamentales de las personas usuarias. En concreto, un uso negligente de las tecnologías digitales podría afectar el derecho de protección de la vida privada de los usuarios, por ejemplo, por medio de un uso no autorizado de su propia imagen o datos personales o sensibles, o afectar su integridad psíquica, por ejemplo, si no se ofreciere suficiente garantía acerca de la seguridad con la cual será tratada su información personal o sensible. Por ello, independiente de si el uso de determinadas tecnologías digitales no se encuentra regulado o no transgrede normas legales, su uso no podrá permitirse si con ello se transgreden derechos fundamentales. Lo anterior, más que obedecer a una obligación jurídica, se trata de un deber ético que emana de la dignidad de las personas y que obliga a respetar los derechos inherentes de todo ser humano por el hecho de ser tal. Para dar cumplimiento a este requisito, creemos que resulta fundamental que los mediadores que deseen incorporar algún tipo de tecnología digital destinen un tiempo razonable de la sesión para explicar con claridad a los usuarios cuáles serían los motivos y alcances de su uso, así como el tipo de datos que podrían ser utilizados y el destino final de la información obtenida. Una vez hecho lo anterior, creemos necesario que el mediador disponga de un consentimiento informado por escrito, para que los usuarios puedan reiterar por sí mismos el conocimiento de la información prestada por el mediador, pudiendo decidir finalmente si se acepta o rechaza su incorporación. Pues no se puede olvidar que cuando hablamos de tratar datos personales lo que en definitiva estamos realizando es un trabajo con aquello que forma parte de la intimidad de la persona y de su vida privada. Por ello, no debiese existir duda alguna respecto de que los usuarios consienten en que el mediador conozca esa información y la utilice con un determinado fin, que, por supuesto, no podría ser extralimitado por el mediador. De lo contrario, si tales finalidades se exceden o si no se cuenta con la autorización de los usuarios para tratar sus datos personales o sensibles, si bien no se transgrediría la ley 19.968 y tampoco la ley 19.628 si el tratamiento no se realiza en bases o registros de datos, en todo caso existiría una vulneración al derecho de protección a la vida privada o de protección de datos personales, o bien de otros derechos fundamentales, como la integridad psíquica, lo cual, en definitiva, sería un atropello a la dignidad de los usuarios del servicio. Creemos absolutamente necesario que se cuente con la firma del consentimiento informado por parte de todos los usuarios involucrados cuando se pretenda utilizar una tecnología que trate los datos personales de al menos una de las partes en conflictos o sus familias, y con la firma de quienes ostentan el derecho de cuidado personal cuando su uso se pretenda para tratar datos personales o sensibles de niños 
o adolescentes. Sin embargo, cuando las tecnologías pudieran ser utilizadas exclusivamente con datos del mediador y contribuir a un mejor servicio, como sucede con audiovisual emotion recognition y MixedEmotions, que podrían ser empleadas con base en un registro visual encuadrado solo en el mediador, no estimamos necesario dicho consentimiento. De esta manera, una vez identificada una tecnología digital que resulte potencialmente útil para el mediador y compatible con la legislación chilena, el mediador deberá ponderar cómo afectaría su uso a los presupuestos teóricos de la mediación, analizando las características de funcionamiento de cada tecnología. Asimismo deberá analizar las características del caso y las suyas propias para evaluar si pudiera explotar las potencialidades observadas sin afectar su desempeño global y si es posible utilizar la tecnología sin transgredir derechos fundamentales. Una vez resueltas estas cuestiones, creemos que el mediador podría contar con la información suficiente para plantear una hipótesis fundada referente a su utilidad en un caso concreto. Es decir, creemos que finalmente, debido a la diversidad de mediadores y de casos en que mediar, teóricamente solo podríamos catalogar una tecnología digital como potencialmente útil, pues su utilidad real deberá evaluarse y comprobarse en la práctica de cada caso.

Por ello, a continuación plantearemos algunos de los potenciales beneficios que observamos en cada tecnología. Considerando el actual vacío que existe en el Sistema Nacional de Mediación Familiar de Chile para responder a la diversidad de lenguas o idiomas de los usuarios que requieren el servicio, creemos que una alternativa prometedora podría derivar del uso de Traduseñas, mivos y Google Translate, pues además de tener el potencial de beneficiar la comunicación y el ejercicio del principio de igualdad y de participación de terceros en la mediación propiamente dicha, consideramos que también tienen el potencial para contribuir a que el Sistema Nacional de Mediación Familiar en su conjunto aborde de forma positiva la diversidad idiomática o de lengua presente en cada solitud de mediación, favoreciendo con ello la inclusión y el goce efectivo del derecho fundamental de acceso a la justicia de familia que poseen todos los ciudadanos. Además, consideramos necesario relevar que estas tecnologías poseen las características de ser económicas, durables y fáciles de utilizar, y que podrían ser menos intrusivas para los usuarios que la participación de un intérprete ajeno al proceso.

Con respecto a audiovisual emotion recognition y MixedEmotions, creemos que su potencial aporte deriva de la posibilidad de contribuir al desarrollo de la inteligencia emocional de los mediadores familiares. Lo anterior, mediante la entrega de información objetiva y continua acerca de su actividad emocional en los procesos de mediación, permitiendo que el profesional pueda autoevaluarse constantemente con base en parámetros objetivos y no en meras impresiones. En este sentido, la retroalimentación objetiva podría ser otorgada al mediador de forma permanente, sin necesidad de depender de procesos de observación de profesionales externos para conocer el desempeño profesional en dicha área. De este modo, mediante estas tecnologías el mediador familiar podría contar con una retroalimentación objetiva para confrontar 
sus hipótesis respecto de la concurrencia de determinadas emociones en el proceso, con lo cual, en casos venideros, podría identificar mejor las emociones tras el lenguaje analógico o digital y con ello determinar mejores vías de gestión en pro del proceso. Esta retroalimentación ex post también serviría para que el mediador aprendiera acerca de cómo expresa sus emociones, y a partir de ello tomar medidas correctivas para mejorar su desempeño en el futuro, resguardando el principio de imparcialidad. A su vez, a partir de esta información creemos que se disminuiría la concurrencia de interpretaciones equívocas respecto de las expresiones faciales, ya que tras una serie de retroalimentaciones el mediador comenzaría a entender el significado objetivamente esperable tras cada expresión facial, con lo cual podría entender y hacer entender a los usuarios su contenido, y se favorecería con ello la comunicación.

Por otra parte, creemos que las funcionalidades de DEus, AdjustWinner, Family Winner, Asset Divider y la Calculadora de pensión de alimentos podrían significar un aporte significativo en los procesos donde al menos una de las personas en conflicto se encontrase arraigada en una posición arbitraria, es decir, alejada de sus intereses, pues para desestabilizar una posición será útil analizarla sobre alguna base que sea independiente de la voluntad de las partes, es decir, información o criterios objetivos como los que pueden ser aportados por estas tecnologías. Del mismo modo, estimamos que estas tecnologías, además de tener el potencial de ayudar al mediador a conducir el proceso hacia el logro de acuerdos, tienen el potencial de contribuir a la secuencia de construcción de confianza con los usuarios, ya que en los casos en que se requiera la realización de cálculos matemáticos complejos que incluyan diversas variables, como sucede en los casos de división de bienes y la determinación de montos de pensión de alimentos, evitarían que el mediador se equivocara en el cálculo matemático y las demoras excesivas para su obtención. Sin embargo, creemos importante recordar que las opciones de solución dadas por estas tecnologías solo deberán ser consideradas meras sugerencias tendientes a enriquecer la creatividad de las partes en conflicto o criterios de referencia para la construcción del propio acuerdo, ya que el contenido del acuerdo final que nace de la mediación debe provenir en todo caso de la voluntad de los usuarios.

\section{Conclusiones}

Con base en todos los elementos analizados podemos concluir que existen tecnologías digitales que podrían beneficiar el ejercicio profesional de los mediadores familiares y que no contravienen las leyes n. ${ }^{\circ} 19.968$ y n. ${ }^{\circ} 19.628$ de la legislación chilena. Estas tecnologías son: audiovisual emotion recognition, MixedEmotions, Traduseñas, MIvos, Google Translate, DEus, AdjustWinner, FamilyWinner, Asset Divider, AffdexMe, EmEx2 y la Calculadora de pensión de alimentos. No obstante lo anterior, para que un mediador familiar pueda determinar de manera completamente fundada si una tecnología digital es potencialmente beneficiosa para su ejercicio profesional, previo a su uso recomendamos estudiar los siguientes factores: 
1. Si la tecnología ofrece o no un potencial beneficio concreto para el planteamiento del discurso inicial, para resguardar los principios de la mediación, para favorecer la comunicación, para gestionar las emociones o para conducir el proceso hacia la búsqueda de acuerdos.

2. Si la tecnología puede o no ser utilizada en armonía con la normativa que regula la mediación familiar y sin transgredir derechos fundamentales.

3. Si la tecnología puede o no ser utilizada sin arriesgar más allá de lo razonable los presupuestos teóricos de la mediación que no se prevén normativamente. Para responder esta pregunta el mediador debe analizar las características de funcionamiento de cada tecnología.

4. Si la tecnología puede o no ser utilizada sin afectar el desempeño global del mediador. Para responder esta pregunta el mediador debe analizar las particularidades del caso y realizar una autoevaluación de sus características personales y capacidades profesionales para valorar si podría explotar las potencialidades observadas en la tecnología sin afectar su desempeño global.

De esta manera, si el mediador responde afirmativamente a los cuatro aspectos planteados, estaría en condiciones de incorporar el uso de la tecnología digital en cuestión a su ejercicio profesional. No obstante, en cada caso en que se pretenda usar la misma tecnología sería recomendable repetir la evaluación del cuarto punto, que se refiere a la capacidad del mediador para valorar las circunstancias del caso y las suyas propias, para estimar cuál sería el impacto del uso de la tecnología en su desempeño global. Esto último contribuiría a que el mediador evite el riesgo de incorporar beneficios aparentes a sus labores que en la práctica podrían hacer aún más complejo su desarrollo, lo cual afectaría la calidad del servicio prestado a las familias. Por lo anterior, finalizamos con la conclusión de que para evaluar en último término si una tecnología digital fue útil para las labores del mediador, la pregunta final debiese estar orientada a evaluar cómo se mejoró el servicio prestado a los usuarios. Pues aun con la comprobación de los cuatro aspectos señalados no resultaría éticamente justificable pretender el uso de tecnologías digitales que podrían tratar datos personales o sensibles de los usuarios, si el fin último de dicha actividad no fuese contribuir a la mejora sustancial del servicio que reciben las familias.

\section{Referencias}

Barsky, A., "The Ethics of App-Assisted Family Mediation", Conflict Resolution Quarterly, Association for Conflict Resolution, 34, 2016, 9-10.

Baugniet, N., "La médiation familiale internationale", en BAugniet, N, La médiation familiale: mode de règlement des conflits familiaux, Paris, De Boeck Supérieur, 2008. 
Bellucci, E., Macfarlane, D. y Zeleznikow, J., "How Information Technology Can Support Family Law and Mediation", Abramowicz, W., Tolksdorf, R. y WĘcel, K. (eds.), Business Information Systems Workshops. BIS 2010. Lecture Notes in Business Information Processing, Berlin, Springer, 2010.

Bellucci, E., y ZelezNiKow, J., "Developing negotiation decision support systems that support mediators: A case study of the Family Winner system", Artificial Intelligence and Law, Springer, 13, 2009.

Bellucci, E., "Software Developed for Use in Family Mediation-AssetDivider", Ceur-WS, 482, 2009

Biblioteca del Congreso Nacional de Chile, Historia de la Ley $n .^{\circ} 19.628,1999$.

Biblioteca del Congreso Nacional de Chile, Historia de la Ley n.o 19.968, 2004.

Biblioteca del Congreso Nacional de Chile, Historia de la Ley $n .^{o}$ 21.096, 2018.

División Judicial, Unidad de Mediación, Bases tipo administrativas y técnicas generales, anexos y contrato tipo, para la contratación de servicios de mediación familiar, 2017.

ESCRIVÁ-Ivars, J., Matrimonio y mediación familiar, Madrid, Rialp, 2001.

Fisher, R., Ury, W. y Patton, B., ¡Sí de acuerdo! Cómo negociar sin ceder, Barcelona, Norma, 1991.

Gervasi, O., Franzoni, V., Riganelli, M. y Tasso, S., “Automating facial emotion recognition", Web Intelligence, Ios Press, 17, 2019.

HERNÁNDEZ, L., “DIRAC crea plataforma digital para mejorar atención a los usuarios”, 2017.

Lavi, D., "Til Death Do Us Part: Online Mediation as an Answer to Divorce Cases Involving Violence", North Carolina Journal of Law \& Technology, University of North Carolina School of Law, 2015.

Mejía, S., Quintero, O. y Castro, J., "Dynamic Analysis of Emotions through Artificial Intelligence”. Avances en Psicología Latinoamericana, 34, n. 2, 2016.

Mera, A., "Mecanismos alternativos de solución de conflictos en América Latina. Diagnóstico y debate en un contexto de reformas", en CEnTRo DE Estudios DE 
Justicia de las AmÉRICAs, Aportes para un diálogo sobre el acceso a la justicia y reforma civil en América Latina, Santiago de Chile, CEJA, 2016.

Mohanmod, S. y Muhammad, G., "Emotion recognition using deep learning approach from audio-visual emotional big data", Information Fusion, 49, 2019.

Morales, G. y García, J., Sistemas y circuitos eléctricos, Madrid, Paraninfo, 2013.

Noroozi, F., Escalera, S., Nuegus, A. y Anbarjafari, G., “Audio-Visual Emotion Recognition in Video Clips". IEEE Transactions on Affective Computing Archive, IEE Xplore, 10, 2019.

Novon, E., Derecho a la vida privada y libertad de información: un conflicto de derechos, Buenos Aires, Siglo XXI, 2001.

Organización para la Cooperación y el Desarrollo Económicos, Perspectivas de la oCDE sobre la economía digital 2017, Ciudad de México, oCDE, 2017.

Poblet, M., Noriega, P., Suquet, J., Gabarró, S. y Redorta, J., “Tecnologías para la mediación en línea: estado del arte, usos y propuestas", en Casanovas, P., Magre, J. y Lauroba, M. (dirs.), Libro Blanco de la Mediación en Cataluña, Barcelona, Huygens, 2011.

Rossi, F., Holtzworth-Munroe, A., Applegate, A., Beck, C., Adams., J. y Hale, D., "Shuttle and online mediation: a review of available research and implications for separating couples reporting intimate partner violence or abuse". Family Court Review, Association of Family and Conciliation Courts, 55, n. ${ }^{\circ}$ 3, 2017.

Suares, M., Mediación. Conducción de disputas, comunicación y técnicas, Buenos Aires, Paidós, 1997.

Suares, M., Mediando en sistemas familiares, Buenos Aires, Paidós, 2002.

The British Columbia Mediator Roster Society, Evaluation of the distance mediation project: Report on Phase II of the Technology-Assisted Family Mediation Project, 2010.

Unión EuRoPeA, "Libro Blanco sobre la inteligencia artificial: un enfoque europeo orientado a la excelencia y la confianza", 2020, 1-31, disponible en [https://op. europa.eu/es/publication-detail/-/publication/aace9398-594d-11 ea-8b81-01aa7 5ed71a1] [consultado el 16 de marzo de 2020]. 
Viollier, P., El estado de la protección de datos personales en Chile, Santiago de Chile, Derechos Digitales, 2017.

Zeleznikow, J., Bellucci, E., Schild, U. y Mackenzie, G., "Bargaining in the shadow of the Law - using utility functions to support legal negotiation", en ICAIL 2007: Proceedings of the 11th International Conference on Artificial Intelligence and Law, Association for Computing Machinery. New York: АCM, 2007.

Zeleznikow, J., y Bellucci, E., "Family Winner: Integrating Game Theory and Heuristics to Provide Negotiation Support", en Bourcier, D. (ed.), Legal Knowledge and Information Systems, JURIX 2003: The Sixteenth Annual Conference. Amsterdam, IOS press, 2003.

\section{Legislación citada}

Constitución Política de la República de Chile, publicada el 22 de septiembre de 2005.

Ley n. ${ }^{\circ} 19.968$, publicada el 30 de agosto de 2004.

Ley n. ${ }^{\circ} 19.628$, publicada el 28 de agosto de 1999.

\section{Otras fuentes}

Boletines n. ${ }^{\circ} 11.144-07$ y n. ${ }^{\circ} 11.092-07$, refundidos.

Gaceta Oficial Distrito Federal, n. ${ }^{\circ}$ 1989, 2014.

Sistema informático Mediare.

Sistema informático Mepre.

[www.dw.com/es/mivos-una-aplicaci\%C3\%B3n-revolucionaria-para-sordos/av42523928]

[www.behance.net/gallery/75582063/TraduSenas-Chile]

[http://mixedemotions.insight-centre.org/]

[https://play.google.com/store/apps/details?id=com.google .android .apps.translate \&hl=es]

[www.divorciofacil.cl/calculadora-pension-de-alimentos/] 